\title{
Effects of using mobile devices on English listening diversity and speaking for EFL elementary students
}

\author{
Wu-Yuin Hwang \\ National Central University \\ Yueh-Min Huang and Rustam Shadiev \\ National Cheng Kung University \\ Sheng-Yi Wu and Shu-Lin Chen \\ National Central University
}

\begin{abstract}
This study designed learning activities supported by a mobile learning system for students to develop listening and speaking skills in English as a foreign language (EFL). How students perceive learning activities and a mobile learning system were examined in this study. Additionally, how different practices relate to students' language proficiency was also explored. It was found that students had positive perceptions and intentions toward learning activities; thus, students were motivated to practice English skills more when using a mobile learning system. The results demonstrated how students' speaking and listening skills practices using mobile devices had different correlations depending on their proficiency levels. For example, listening diversity, defined as the number of other classmates a student listened to, was found to have an inverse correlation with speaking and listening proficiency. This finding does not support previous research and indicates that students who carefully selected their listening partners performed better than those who did not. It was further found that the better students performed in English learning, the fewer partners they would choose. EFL instructors can use the insights of this study to design more effective language learning activities for students using mobile devices.
\end{abstract}

\section{Introduction}

In today's world, English has become one of the primary languages in many fields, including academic discourse, business, technology, and international relations (Shadiev, Hwang, Chen, \& Huang, in press; Shadiev, Hwang, Huang, \& Liu, in press; Sun, Huang, \& Liu, 2011; Wu, Sung, Huang, Yang, \& Yang, 2011). Both professional and personal language proficiency involves well-developed listening, speaking, reading, and writing abilities (Hwang, Chen, Shadiev, Huang, \& Chen, 2012). However, there are limited opportunities to speak English or listen to a speech in English in countries where it is not an official language (Hwang et al., in press; Hwang \& Shadiev, 2014). According to Cheon (2003) and Tsou (2005), in countries of the Asia-Pacific region such as South Korea, Japan, and Taiwan, reading and writing are emphasized far more than listening and speaking, particularly in elementary schools. Several factors lead to this lack of oral and listening practice, including the absence of an English context to stimulate speaking and listening, the instructors' lack of confidence, or the deficiency of good spoken English examples, and excessive dependence upon traditional teaching techniques. Cultural factors are also important. Asian students are assumed to be able to perform well in public, and such performance pressure causes anxiety and silence, which leads to less voluntary participation in class discussion. Therefore, students are more willing to read and write, avoiding interaction with others when learning English. This makes learning English less interesting, and reduces students' learning motivation.

Research on English as a foreign language (EFL) learning suggests that listening and speaking are core elements of interaction (Ghoneim, 2013). Therefore, the importance of practicing listening and speaking skills cannot be more emphasized, as it has a direct and positive influence on learning performance (Hwang \& Chen, 2013; Hwang, Shadiev, \& Huang, 2011). For example, Kukulska-Hulme and Shield (2008) indicated that practicing in pairs can increase practice opportunities, and thus help students in EFL contexts. Furthermore, Hwang and Chen (2013) suggested that imitation and revision are important language practice activities in pairs.

The relationship between language practice and learning performance has been widely investigated. According to Hwang and Chen (2013), Hwang et al. (in press), and Hwang et al. (2011), the more 
students practiced speaking and listening, the better skills they acquired, especially those who speak English as a foreign language, because they usually only practice speaking in class. Consequently, the longer EFL students spent on practicing skills such as speaking (Hwang et al., in press; Hwang, Wu, \& $\mathrm{Su}, 2008$ ), rehearsing (Thorton \& Houser, 2005), and listening (Hazan, Sennema, Iba, \& Faulkner, 2005), the better their speaking and listening skills became. That is, more involvement and time spent on interaction positively influenced the EFL ability of the learner (Ghoneim, 2013). Listening diversity was considered to enhance students' real understanding (Bueschel, 2008). It enables students to listen to not only the speech of a single student but multiple students with a diversity of speaking styles (i.e. accent, fluency, and level of learning performance). However, which types of listening and speaking practice are able to effectively bring out positive learning outcomes is a question that requires consideration. For instance, it is still unclear whether listening to self-recorded speech is better for EFL skills than listening to others' speech (i.e. peers or the teacher). Furthermore, little is known about how much students can benefit from exercising EFL skills with diverse students, e.g. students who perform equally or worse.

To diminish those uncertain factors mentioned above, the possibility of mobile technology to facilitate language learning was discussed in related studies. Hwang and Chen (2013) and Hwang et al. (2012) showed that use of mobile devices in collaborative EFL activities reduces students' stress and facilitates collaboration in English learning. Jeng, Wu, Huang, Tan and Yang (2010) suggested that mobile technology can offer students multimedia interaction with their peers, like listening to each other and recording their spoken production. Furthermore, mobile technology makes it more convenient for students to conduct a wide range of activities, particularly those that can make students interact with each other and share what they have learned. Developing listening and speaking skills with the assistance of mobile technology was extensively discussed by Hwang and Chen (2013), Liu and Chu (2010), Nah, White and Sussex (2008), and Wang, Shen, Novak and Pan (2009). However, learning material and activities designed in their studies were less diverse; thus a practice of listening and speaking skills was limited. For instance, Nah et al. (2008) had students listen to some audio files which contained key vocabulary only. In the study of Liu and Chu (2010), Nah et al. (2008), and Wang et al. (2009), audio files for listening skills were prepared and voiced only by one speaker, mostly by the teacher. That is, students did not have enough opportunities to listen to other learning materials such as dialogues or stories by diverse speakers. Learning activities designed by Wang et al. (2009) were interactive, but unfortunately students could only use short text messages to respond to teachers' questions. In a study by Hwang and Chen (2013), and Liu and Chu (2010) students could only verbally communicate using newly learnt vocabulary or a few simple sentences.

This study strived to overcome the limitations mentioned above and designed various learning activities supported by mobile technology. Guided by related literature, activities were designed in such a way that students could freely practice and then improve their EFL speaking and listening skills. For example, they spoke using not only new vocabulary and sentences but also dialogues and short stories. Further, some activities for speaking practice were designed to create student interaction when students conversed or created short stories with peers in a relay style activity. Students recorded their speaking and then shared with peers. During listening practice, students could listen to their own recordings as well as those made by peers or the teacher.

This study aimed to investigate students' perceptions and intentions regarding learning activities supported by mobile technology, the relationship between students' perceptions and intentions, and the relationship between students' intentions and actual system usage for practicing speaking and listening skills. Furthermore, this study aimed to examine the relationship between different types of EFL speaking and listening practice using mobile technology and learning achievement, which was not the focus of most previous studies.

This study has contributed to scholarship in this area in the following ways. First, related studies on technology-assisted EFL learning were analyzed and some limitations (e.g. related to learning activities) were revealed, so better and more specific learning activities supported by mobile learning technology were designed to facilitate the development of EFL speaking and listening skills. Second, this study investigated how students perceive such learning activities and the relationship between their perceptions, intentions, and actual system usage for practicing EFL speaking and listening skills. Furthermore, this study examined what type of practices can have positive learning outcomes by providing evident data. 
Third, this study discussed results and provided several implications and suggestions for future study design and research.

\section{Literature review}

\section{Mobile technology-assisted language learning}

The potential of mobile technology to assist language learning was discussed in numerous studies (Huang \& Chiu, 2014). Kukulska-Hulme and Shield (2008) stated that m-learning (mobile learning) can offer a language learning experience where students are able to enjoy learning anytime and anywhere. According to Chen, Hsieh and Kinshuk (2008), and Huang and Chiu (2014), m-learning can aid both formal learning in traditional classrooms and informal settings outside classes, thus increasing access to learning activities and engagement in learning tasks in and outside the classroom. Furthermore, mobile devices allow students to coordinate and interact more easily and thus enable them to carry out collaborative learning (Huang, Chiu, Liu, \& Chen, 2011; Huang \&Wu, 2011; Huang, Huang, Huang, \& Lin, 2012).

Recently, more and more language teachers have become interested in Mobile Assisted Language Learning (MALL), and have considered how to employ mobile devices in their classes (Chen et al., 2008; Liang \& Huang, 2014; Huang et al., 2012; Hwang \& Chen, 2013; Hwang et al., 2012; Thorton \& Houser, 2005; Wu et al., 2011). In their overview paper, Kukulska-Hulme and Shield (2008) noted that MALL uses personal, portable devices that enable new ways of learning, emphasizing continuous and spontaneous access and interaction across different usage contexts. Furthermore, it was noted that mobile learning is student- rather than teacher-led because mobile devices are more closely related to individuals' specific contextual needs. Therefore, when designing activities or applications for mobile learning, how mobile devices can be used to meet individual and contextual needs is an issue to be considered (Huang et al., 2012; Hwang, \& Chen, 2013; Hwang et al., 2012; Wu et al., 2011).

Murray and Barnes (1998) suggested that technology applied to assist language learning needs to be evaluated on a pedagogical basis. Murray and Barnes (1998) have identified "ease of use" as a major factor in the adoption of a technology for foreign language learning. In this study, a mobile learning system is integrated to help English language learning with a focus on speaking and listening skills, applications of the system for language acquisition are evaluated, and important supporting evidence is provided, as shown in later sections.

\section{Developing listening and speaking skills with the assistance of mobile technology}

Of particular interest in this study is our focus on listening and speaking skills, on which many researchers have conducted prior studies. For example, Nah et al. (2008) investigated the potential of using a mobile phone to browse wireless application protocol (WAP) sites for the purpose of developing EFL listening skills. One experiment was carried out with undergraduate students who took an intermediate EFL listening course. During the experiment students accessed WAP sites to participate in pre-listening, during-listening, and post-listening activities. During the activities, students listened to key vocabulary and audio files and then discussed activity questions. Results of the study showed that students expressed positive attitudes towards the use of the technology. Furthermore, results demonstrated that the technology was effective for students' development of listening skills.

Wang et al. (2009) also studied the impact of mobile technology on EFL students' learning behaviors and performance in a large blended classroom. A mobile learning (m-Learning) system was developed in the study and it delivered live broadcasts of real-time classroom teaching to students with mobile devices. The system featured short text messaging and instant polls so that students could answer the teacher's questions in real time. For example, through the m-Learning system the instructor taught situational dialogues and showed exercises in live broadcast, and students replied within the given timeframe via text messages. This study found that m-learning activities encouraged students to engage in the learning process more. Furthermore, results of this study revealed that students turned out to become more active and truly engaged learners.

Moreover, Hwang and Chen (2013) developed a mobile listening and speaking practice system for EFL learning. One experiment was conducted by Hwang and Chen (2013) to compare the performance of the 
control group (i.e. students learned by using paper-based learning materials) and the experimental group (i.e. students learned by using learning materials with personal digital assistants). Results of the experiment revealed that the experimental group significantly outperformed the control group in language proficiency. According to results of this study, students could repeatedly record their own voices and listen to themselves and others' recordings using personal digital assistant (PDA), thus obtaining more opportunities to practice and improve their language proficiency.

Liu and Chu's study (2010) introduced games into an English listening and speaking course and then investigated how games influence English learning achievement and motivation in a mobile learning environment. In the study, high school students participated in an experiment in which they were divided into two groups to learn with the same learning activities yet with different learning devices; the control group learned with $\mathrm{CD} / \mathrm{MP} 3$ players and printed materials while the experimental group learned with mobile devices. The learning activities in this study were called Campus Environment, Campus Life, and Campus Story. To be involved in the learning activities, students used a campus map and moved the game character into or went to different learning zones on a map. When the character or students reached one of zones (e.g. library), the system generated a learning material related to that zone available for students to practice their language skills. For example, a student could watch an English movie clip to practice listening skills, or converse with a virtual learning tutor about a library-related topic to practice speaking skills. Furthermore, students created stories in relay and recorded stories using PDA phones. After the experiment, evaluation of learning outcomes and learning motivation demonstrated that incorporating learning games supported by the mobile technology into the English learning process could achieve better learning outcomes and motivation.

\section{Research questions}

This study designed various learning activities supported by mobile technology to facilitate EFL listening and speaking skills. Furthermore, this study aimed to investigate students' perceptions and intentions regarding learning activities supported by mobile technology, the relationship between students' perceptions and intentions, and the relationship between students' intentions and their EFL speaking and listening skills development using mobile technology. More importantly, this study aimed to analyse the relationship between learning achievement and different types of EFL speaking and listening skills practises by using mobile technology. The following research questions were examined in this study:

1. What are students' perceptions and intentions regarding using a mobile learning system in developing English listening and speaking skills?

2. Are students' perceptions toward learning activities supported by a mobile English listening and speaking system related to their intentions to use the system?

3. What is the relationship between students' intentions and actual system usage?

4. What factors explain students' learning achievement using a mobile English listening and speaking system?

5. Can students' listening and speaking skills development be predicted after using a mobile English listening and speaking system?

\section{Research design}

\section{Research framework}

The research framework of this study (see Figure 1) was designed based on the Technology Acceptance Model (TAM) (Davis, 1989). In order to facilitate students' listening and speaking skills, learning activities that were designed in this study were supported by a mobile English listening and speaking system. Thus, this study aimed to explore how students perceive the learning activities and system, students' intentions to use system, and their actual system usage. Furthermore, this study aimed to analyze the relationship between variables of students' perceptions (i.e. system ease of use, system usefulness, activities playfulness, and activities usefulness) and intentions to use the system. The relationship between variables of system usage (i.e. recording times, listening diversity, listening involvement, listening times, rehearsal times, and times listened to) and learning achievement was also investigated. 


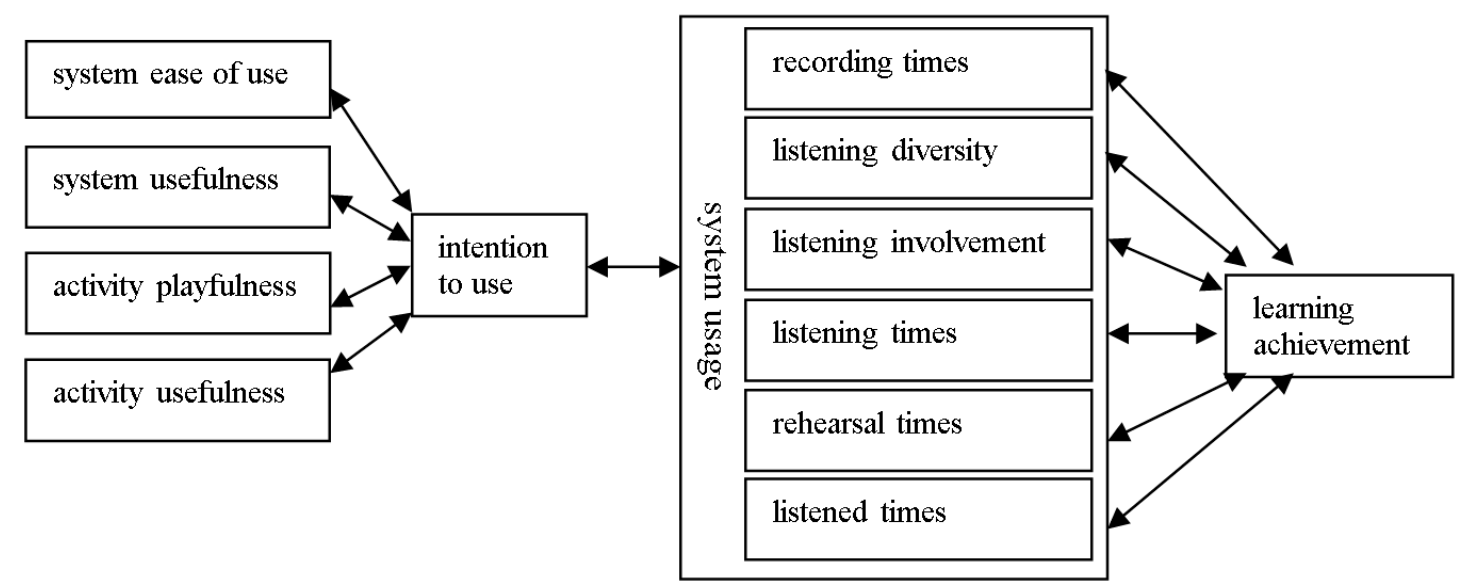

Figure 1. Framework of the study

\section{The design of learning activities}

Guided by recommendations from previous related research, this study designed six learning activities supported by a mobile English listening and speaking system. In contrast to previous research, learning activities in this study enabled students to freely practice their EFL listening and speaking skills and in more diverse ways. For example, during learning activities, students used not only new vocabulary and sentences but also dialogues and short stories individually as well as collaboratively with peers. Students recorded their speaking and then shared recorded files with peers. More importantly, students could listen to self-recorded speech as well as to the speech of peers and the teacher. Learning activities were carried out in a sequence from easy to difficult and with elements of fun to motivate students to practice their language skills without pressure and anxiety.

Vocabulary repetition: This activity was designed to provide basic speaking skills practice and vocabulary building. A PDA showed target vocabulary on the screen that students could follow and verbally repeat (Figure 2a). Students then used a PDA touch pen to write down the vocabulary shown on the screen and verbally repeat. Meanwhile, with the PDA's built-in microphone, students recorded their voice so that they could listen to it afterwards. Further, all recorded files were uploaded online and shared among classmates.
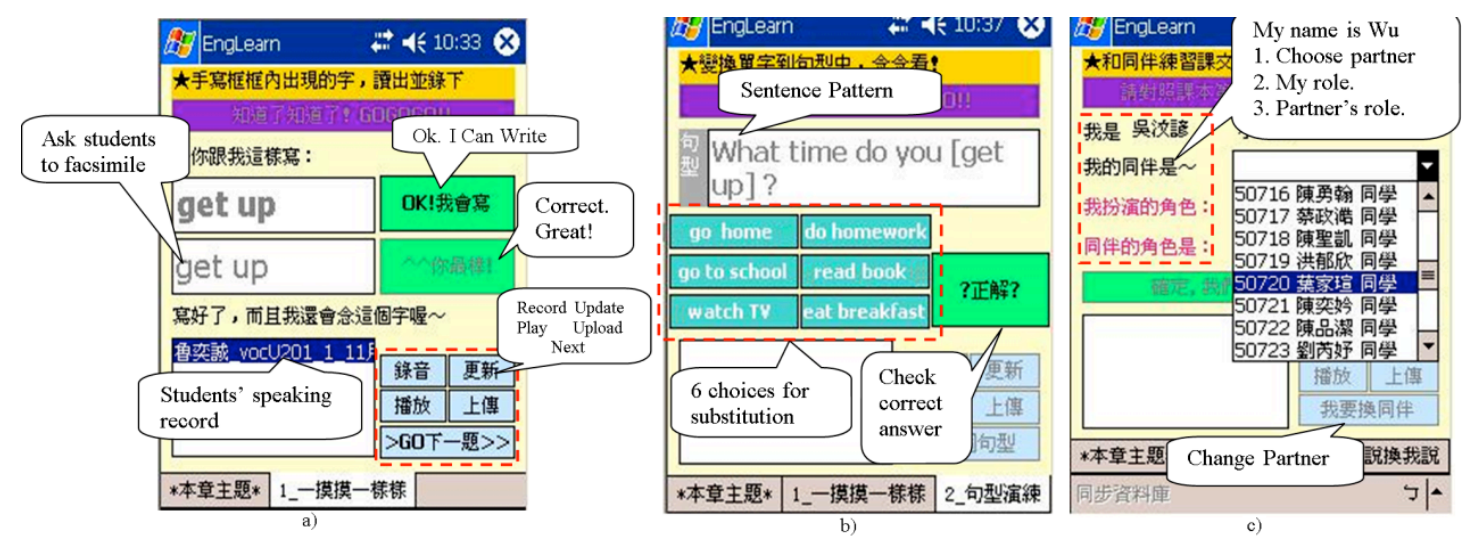

Figure 2. Learning system interface for: (a) vocabulary repetition, (b) sentence pattern substitution, and (c) role-play activities

Sentence pattern substitution: A PDA displayed a sentence with a key word (in square brackets) and six alternative words (with some incorrect) that students used to substitute a key word (Figure 2b). The mobile system would show if the substitution is correct or not. If the substitution task was completed correctly, what students would do next is to speak the sentence and record it to share with others. Students listened to their own and others' recordings afterwards. 
Role-play: Each student was invited to choose a partner and a role to act for this activity. Students then acted out a role-play story using a script from learning material and recorded it (Figure 2c). Later, all audio recorded files were uploaded to share on the database so that students could listen to all shared recordings.

You speak, then I speak: A PDA displayed a sentence that students needed to repeat and students recorded their voice to share recorded files with classmates. This activity enabled students to listen to diverse pronunciations of different students, including pre-recorded pronunciation of a sentence by the teacher.

Brainstorming - photos and words: A PDA displayed a photo and three words, one corresponded to the photo and two did not. Students worked in small groups and they were asked to find which word corresponded to the photo. If students selected the right one, the mobile system would display a sentence containing that word, the so-called target word. Students were then asked to brainstorm to make another sentence/s or a conversation using the target word. Similarly to the other exercises, students verbalized the sentences they wrote and recorded them, and then shared the recording with other groups.

Photos, voices, and words: This activity was carried out individually first and then in small groups. A PDA displayed a picture and three words with only one matching the picture so that each student had to find that target word. After students selected the correct word, i.e. the one that matched the picture, the system displayed a sentence with the target word, and students repeated the whole sentence. Students then were randomly grouped and were asked to brainstorm to make other sentences or conversations with the target word from the individual work. Students also discussed other words they have learnt with similar vowels to the word from the individual work.

\section{Participants}

This study was carried out throughout one semester with one class of 35 fifth-grade elementary school students (10 or 11 years old). Two students did not accomplish all learning activities so were excluded from data analysis; thus, the valid number of participants in this study was 33 . All students had two years of foreign language learning experience prior to this study. None of the students had previous language acquisition experience using mobile devices but did have experience using computers and Internet. Therefore, all students were trained to use the proposed learning system on mobile devices before working on any learning activities.

\section{Research Tools}

A questionnaire survey was administered to investigate how students perceive learning activities and the mobile English listening and speaking system (Please contact the corresponding author for a copy of both the pre- and post-test questionnaires). The questionnaire survey was designed based on TAM proposed by Davis (1989) and it was aimed at evaluating how users come to accept and use technology. Five dimensions were covered in the questionnaire:

1. Perceived ease of use of the system (PEU) - the degree to which a student believes that using the mobile English listening and speaking system would be free from effort;

2. Perceived usefulness of the system (PU) - PU is the degree to which a student believes that using the mobile English listening and speaking system would enhance his or her learning performance;

3. Perceived playfulness of the activities (PPA) - the degree to which a student believes that the learning activities would fulfill his/her intrinsic motivation (Moon \& Kim, 2001);

4. Perceived usefulness of activity (PUA) - PUA is the degree to which a student believes that participating in the learning activities would enhance his or her learning performance (Huang, Huang, \& Wu, 2014; Huang, Huang, Liu, \& Tsai, 2013; Hwang \& Chen, 2013; Hwang et al., 2012);

5. Intention to use the system (IU) - IU is hypothesized to be a major determinant of whether or not a person actually uses the mobile English listening and speaking system.

To perfect the model, Venkatesh and Davis (2000) developed TAM2 by correcting the shortcomings of TAM. TAM2 incorporates additional theoretical constructs spanning social influence processes (subjective norm, voluntariness, and image) and cognitive instrumental processes (job relevance, output 
quality, and result demonstrability). However, constructs related to social influence and cognitive instrumental processes were not included in the questionnaire survey because this study explored the PEU and PU of the mobile English listening and speaking learning system, and students' attitudes toward it.

Items of the questionnaire survey were edited (i.e. rephrased) by the teacher in this study to make the items more easily understood by students. Furthermore, the teacher would explain whenever students didn't understand any items of the questionnaire. The questionnaire survey was paper-based and was completed by all students within one hour of completing all learning activities.

This study ranked responses to the questionnaire using a five-point Likert scale, anchored by the endpoints "strongly disagree" (1) and "strongly agree" (5). The Cronbach $\alpha$ was adopted to assess the internal consistency of the survey (Creswell, 2012). The values for the five dimensions were higher than 0.7, which indicated the reliability of the questionnaire.

Data related to system usage of participants was collected by the system and categorized into following six variables:

a) Listening diversity: the number of different participants a student listened to.

b) Listening involvement: the average number of listening times a student listened to participants. The average number was calculated by adding the number of listening times a student listened to participants and then dividing by the number of participants a student listened to. The higher the listening involvement a learner had, the more was the average number of listening times a student listened to participants' recordings. Therefore, this variable can be employed to represent the depth or engagement of listening performed by a student.

c) Recording times: the number of voice recordings recorded by a student.

d) Listening times: the number of times a student listened to other students' voice recordings.

e) Rehearsal times: the number of times a student listened to his/her own voice recordings.

Field notes of learning scenarios and learning behaviors in which students developed listening and speaking skills by using the system were taken regularly and systematically by observation throughout the study. Researchers and the teacher were involved in writing field notes to ensure the reliability and validity of collected data. One-on-one semi-structured interviews with subsequent data analysis followed the general recommendations of Creswell (2012) and Shadiev et al. (in press). The interviews contained open-ended questions in which students were asked about: 1) their experience using the system during the study; and 2) their opinions about the impact of learning activities supported by the system for learning. Each interview took approximately 30 minutes; all interviews were audio-recorded with the permission of the interviewee and then fully transcribed for analysis. Segments from the field notes and interviews that answered research questions in this study were highlighted and coded. Next, codes with similar meanings were categorized together. Established categories formed a framework to report findings to the research questions.

It is worth mentioning that the participating instructor was not the researcher in this study. Thus, there were no power relationships influencing student responses to the questionnaire survey or interviews.

Listening and speaking scores of the pre-test and post-test were used to measure students' language proficiency. The tests were designed by the elementary school teacher with more than 10 years of EFL teaching experience based on the learning materials and activities of this study. According to the teacher, items of the tests had the same structure, different content, and equivalent degree of difficulty. For example, in Item 4 of the pre-test, time when class starts was mentioned as 8:30am, while in the same item of the post-test, time when class ends was mentioned as 9:30am. In Item 9 of the pre-test, students were asked "What time do you go to school?" and provided with three possible answers: 1) I go to school at 7:00am; 2) I eat lunch at 7:00am; 3) I go to bed at 7:00pm. On the other hand, the question in Item 9 of the post-test was "What time do you do homework?" with the three possible answers as 1) I get up at 6:00am; 2) I eat dinner at 6:00pm; 3) I do homework at 6:00pm. Both examples show that the structure of the questions and answers were the same, however, most words that constitute the questions and answers were different. Such an approach was employed to ensure that students could not memorize the answers after taking the pre-test, so that the post-test could fairly evaluate students' language proficiency. 
The pre-test was carried out in the first class and the post-test was carried out in the last class; both tests took place for around one hour. During the listening part of the test, several audio records were played and students were asked to choose from the list, correct first letters, vowels, and words as well as to write the correct time in words. During the speaking part of the test, students were provided with words and pictures to choose the correct picture-word match and speak it out loud.

Students were divided into two groups, high proficiency and low proficiency, based on their English language proficiency. Nine students with scores in the top $27 \%$ of the class were allocated to the high proficiency group while the other nine students whose scores fell below $27 \%$ were allocated to the low proficiency group.

\section{Results and discussion}

\section{Analysis of students perceptions and behavioral intentions}

According to results of the questionnaire survey, most students of this study had positive perceptions toward the system; in terms of system ease of use $(M=4.49 ; \mathrm{SD}=0.61)$, system usefulness $(\mathrm{M}=4.24$; $\mathrm{SD}=0.79)$, and intention to use the system $(\mathrm{M}=4.52 ; \mathrm{SD}=0.62)$. Moreover, most students agreed that activities were playful $(M=4.20 ; S D=0.73)$ and useful $(M=4.26 ; S D=1.05)$. Results suggest that, in general, students of this study positively accepted the system and learning activities.

\section{The relationship between variables of students' perceptions and behavioral intentions}

By using the Pearson product-moment correlation coefficient, this study examined how students' perceptions are related to their behavioral intentions. Pearson's correlation is a measure of the linear correlation between two (or more) variables. According to Creswell (2012), the sample needs to be of adequate size for use of correlational statistics (at least $\mathrm{N}=30$ ). Larger sizes contribute to less error variance and better claims of representatives.

Results of Pearson's correlation indicate that system ease of use has a significant correlation with intention to use $(r=0.437, \mathrm{p}<0.05)$. This may suggest that the easier the students regarded the system to use, the stronger their intention to use the system was. Results showed that system usefulness and students' intention to use significantly correlate with each other $(r=0.748 ; \mathrm{p}<0.001)$. This implies that students may have stronger intention to use the system if they find it more useful than they expect. However, results indicate that the relationship between system usefulness and intention to use was much stronger, when compared to the relationship between system ease of use and intention to use. According to students' perception, it is system usefulness but not system ease of use that had a greater influence on students' willingness to use the system. These results are in line with those related to the technology acceptance model (Davis, 1989). Furthermore, significant correlations were found between activity playfulness and intention to use $(r=0.782 ; \mathrm{p}<0.001)$, and between activity usefulness and intention to use $(r=0.548 ; \mathrm{p}<0.01)$. These results suggest that activity playfulness and usefulness could strongly drive students' willingness to use the system. To be more specific, the more playful and useful students regarded the activities, the greater was their intention to use the system. This finding echoes other related studies (Hwang \& Chen, 2013; Hwang et al., 2012).

\section{Predicting intention to use the system on the basis of perceptions toward the system and learning activities}

Multiple regression analysis was conducted to investigate how students' perceptions toward the system and learning activities might contribute towards intention to use the system. Results of the analysis are shown in Table 1. The results of the variance inflation factor (VIF) and tolerance (tolerance $>0.1$ ) tests indicate that no significant multicollinearity existed among the variables. The prediction model was statistically significant $(\mathrm{F}=12.404, p<0.001)$ and accounted for approximately $58.8 \%$ of the variance in intention to use $\left(\mathrm{R}^{2}=0.639\right.$, Adjusted $\left.\mathrm{R}^{2}=0.588\right)$. 
Table 1

Results of multiple regression analysis to predict intention to use the system

\begin{tabular}{llllll}
\hline & Variables & $\mathrm{B}$ & $\beta$ & $\mathrm{t}$-value & VIF \\
\hline $\mathrm{R}^{2}=.639$ & System ease of use & .019 & .036 & .251 & 1.565 \\
Adj. $\mathrm{R}^{2}=.588$ & System usefulness & .056 & .270 & 1.094 & 4.717 \\
$(\mathrm{~F}=12.404, \mathrm{p}=.000)$ & Activity playfulness & .011 & .023 & .134 & 2.238 \\
& Activity usefulness & .102 & .524 & $2.473^{*}$ & 3.486 \\
\hline
\end{tabular}

p $<.05$

\section{The relationship between intention to use the system and variables of system usage}

The correlation between intention to use and variables of system usage was tested by using Pearson correlation analysis. According to results, it is interesting to note that the correlation was not significant. That is, although students had a strong intention to use the system, the level of system usage was still low. A possible explanation for this finding might be that as there was no after-class activity designed in this study, the mobile system was only used in class and PDA devices were taken back by the teacher immediately after each class had finished. Similar findings were reported by Hwang et al. (2011), however, students in their study used web-based multimedia annotation systems for EFL learning.

\section{Analysis of the pre-test and post-test difference}

First, this study administered paired samples t-tests to explore the difference between the pre- and posttest of students. Descriptive statistics (Table 2) show that the pre-test's mean $(\mathrm{M}=83.76 ; \mathrm{SD}=15.60)$ was lower compared to the post-test's mean $(\mathrm{M}=88.24 ; \mathrm{SD}=10.64)$. Moreover, results of statistical analysis showed that there was the significant difference between values of the pre-test and post-test $(\mathrm{t}=-2.997$; $\mathrm{p}<0.05$ ). This result may suggest that there was a significant learning gain, in terms of language proficiency, which resulted from application of learning activities supported by the mobile system.

Table 2

Results of paired samples t-test analysis to explore the pre-test and post-test difference

\begin{tabular}{lllll}
\hline & $\mathrm{M}$ & $\mathrm{SD}$ & $\mathrm{t}-\mathrm{value}$ & $\mathrm{df}$ \\
\hline Pre-test & 83.76 & 15.60 & $-2.997^{*}$ & 32 \\
Post-test & 88.24 & 10.64 & & \\
${ }^{*} \mathrm{p}<.05$ & & & &
\end{tabular}

Second, this study conducted further investigation into the relationship between six variables of system usage and students' language proficiency by using the Pearson product-moment correlation coefficient. Results of correlation analysis are shown in Table 3. According to results, only recording times $(r=0.572$; $\mathrm{p}<0.01)$, listening diversity $(r=-0.516 ; \mathrm{p}<0.01)$, listening involvement $(r=0.606 ; \mathrm{p}<0.001)$, and listening times $(r=0.646 ; \mathrm{p}<0.001)$ had significant correlation with language proficiency. Results suggest that the more oral exercises that were recorded, the higher the language proficiency that could be obtained. Results also suggest that the higher the listening involvement was, and the more times students listened to recordings, the higher the language proficiency achieved. On the other hand, it can be concluded from results that the more diverse the recordings students listen to are, the worse their language proficiency.

Table 3

Results of Pearson correlation analysis between system usage and language proficiency $(n=33)$

\begin{tabular}{lllllll}
\hline & $\begin{array}{l}\text { Recording } \\
\text { times }\end{array}$ & $\begin{array}{l}\text { Listening } \\
\text { diversity }\end{array}$ & $\begin{array}{l}\text { Listening } \\
\text { involvement }\end{array}$ & $\begin{array}{l}\text { Rehearsal } \\
\text { times }\end{array}$ & $\begin{array}{l}\text { Listening } \\
\text { times }\end{array}$ & $\begin{array}{l}\text { Listened } \\
\text { to times }\end{array}$ \\
\hline $\begin{array}{l}\text { Language } \\
\text { proficiency }\end{array}$ & $.572^{* *}$ & $-.516^{* *}$ & $.606^{* * *}$ & .079 & $.646^{* * *}$ & .241 \\
\hline
\end{tabular}

$\mathrm{p}<.01,{ }^{* * *} \mathrm{p}<.001$

Data derived from the field note analysis and interviews suggest that a negative correlation between listening diversity and language proficiency may be explained by examining the behavior of students 
listening to recordings, namely whose recording they choose to listen to. For most students, listening to recordings of their friends but not to recordings of outperforming classmates was the first priority. Therefore, when such students listened to a recording of one friend and had difficulty understanding it, he could switch to a recording of another friend, and so on. These students listened to recordings of many other students (i.e. listening diversity) but did not benefit from it greatly. On the contrary, students with good performance usually listened to recordings of students with the same or higher performance; yet, these students are not the majority. That is, these students tend to think that they can learn more from those whose English is equally good or even better, instead of from those with lower performance. Therefore, students with good performance strategically selected limited partners' recordings to listen to (i.e. less listening diversity). Based on this finding, it is suggested that educators can encourage students to learn from each other, i.e. peer-initiated learning. High-performance students can learn more from teaching those who need extra help and support. Low-performance students can listen to recordings from those who performed better or recordings made by the teacher, instead of listening to recordings of their friends who usually performed the same or even worse.

Results of this study did not show any significant correlation between number of times listened to and language proficiency and between rehearsal times and language proficiency. A possible explanation for this might be derived from the observation of learning scenarios and behaviors of students. Most students preferred to listen to recordings made by their good friends first, and then to those recorded by students who performed better. On the other hand, listening to their own recordings was nothing more than recognizing their own voice in English; however, listening to recordings of students with better performance helped language proficiency. It was found that imitating others' voices was more interesting.

These findings are in line with results obtained by Bueschel (2008), Ghoneim (2013), Hazan et al. (2005), Hwang and Chen (2013), Hwang et al. (2011), and Thorton and Houser (2005). However, they suggested that listening diversity, rehearsal times, and times listened to are also useful to enhance language proficiency, which contradicts with findings of this study.

\section{Predicting language proficiency on the basis of variables of the system usage}

This study conducted multiple regression analysis to investigate how variables of the system usage, such as recording times, listening diversity, listening involvement, listening times, rehearsal times, and times listened to influence language proficiency. Results of the analysis are shown in Table 4. The results of the Variance Inflation Factor (VIF) and tolerance (tolerance $>0.1$ ) tests indicate that no significant multicollinearity existed among the variables. According to Table 4, language proficiency was primarily predicted by listening times, secondarily by recording times, and thirdly by listening diversity (with negative value). The prediction model accounted for approximately $57.8 \%$ of the variance in language proficiency $\left(\mathrm{R}^{2}=0.618\right.$, Adjusted $\left.\mathrm{R}^{2}=0.578\right)$.

Table 4

Results of multiple regression analysis to predict language proficiency

\begin{tabular}{|c|c|c|c|c|c|c|c|}
\hline & $\mathrm{R}^{2}$ & Adj. $\mathrm{R}^{2}$ & Variables & $\mathrm{B}$ & $\beta$ & t-value & VIF \\
\hline Model 1 & .417 & .398 & Listening times & .378 & .646 & $4.708^{* * *}$ & 1.000 \\
\hline \multirow[t]{2}{*}{ Model 2} & .515 & .483 & Listening times & .258 & .486 & $3.405^{* *}$ & 1.260 \\
\hline & & & Recording times & .167 & .351 & $2.462^{*}$ & 1.260 \\
\hline \multirow[t]{3}{*}{ Model 3} & .618 & .578 & Listening times & .182 & .311 & $2.172^{*}$ & 1.557 \\
\hline & & & Recording times & .194 & .406 & $3.117^{* *}$ & 1.289 \\
\hline & & & Listening diversity & -.902 & -.358 & $-2.796^{* *}$ & 1.242 \\
\hline
\end{tabular}

$\mathrm{p}<.05,{ }^{* *} \mathrm{p}<.01,{ }^{* * *} \mathrm{p}<.001$

This result suggests that listening times, recording times, and listening diversity (with negative value) can predict language proficiency. The regression model formula is thus:

Language proficiency $=.311 \times$ listening time $+.406 \times$ recording time $+-.358 \times$ listening diversity

\section{Analysis of the system usage by the high and low proficiency groups}


The independent samples t-test was carried out to analyze the difference in using the system between students in the high and low proficiency groups. Results of the analysis are presented in Table 5. The results imply that recording times completed by low proficiency group $(\mathrm{M}=71.42 ; \mathrm{SD}=27.06)$ were fewer than those by the high proficiency group $(\mathrm{M}=82.29$; $\mathrm{SD}=18.69)$, listening times were fewer for low proficiency group $(\mathrm{M}=34.00 ; \mathrm{SD}=13.42)$ than for the high proficiency group $(\mathrm{M}=56.38 ; \mathrm{SD}=15.39)$, listened to times were fewer for the low proficiency group $(\mathrm{M}=4.75 ; \mathrm{SD}=3.13)$ than for the high proficiency group $(\mathrm{M}=11.67 ; \mathrm{SD}=9.57)$, and listening involvement was less for the low proficiency group $(M=2.45 ; S D=1.07)$ than for the high proficiency group $(M=7.20 ; S D=3.22)$. From the figures in Table 5, students of low proficiency didn't practice as much as those of high proficiency in terms of involvement of recording times, listening times, listened to times and overall listening engagement. However, what is interesting to notice was that the low proficiency group scored higher than the high proficiency group in the area of listening diversity $(\mathrm{M}=14.08 ; \mathrm{SD}=2.99)$ vs. $(\mathrm{M}=9.14 ; \mathrm{SD}=3.77)$ and rehearsal times $(\mathrm{M}=101.50 ; \mathrm{SD}=34.12)$ vs. $(\mathrm{M}=95.52 ; \mathrm{SD}=19.79)$. These results may suggest that two groups had different system usage statistics due to other variables not accounted for, for example a student's speed. Perhaps some students did not fully understand how to use PDAs for language learning and therefore their involvement in using the system became low. That is, these students might access learning materials less as well as have engaged in learning activities less, therefore, their proficiency turned out to be lower in the language proficiency test. To refute this argument, this study confirms that most students agreed that the mobile system was easy to use $(\mathrm{M}=4.49 ; \mathrm{SD}=0.61)$, as shown in the questionnaire survey results. Furthermore, all students were trained to use the mobile system on PDAs before participating in learning activities and students were allowed to start learning activities only after they confirmed that they had been familiar with the system and learning activities.

Table 5

Results of independent sampling t-test analysis in system usage between high and low proficiency groups

\begin{tabular}{llll}
\hline & M & SD & t-value \\
\hline Recording times & 71.42 & 27.06 & -1.233 \\
$\quad$ Low proficiency & 82.29 & 18.69 & \\
High proficiency & & & $3.882^{* *}$ \\
Listening diversity & 14.08 & 2.99 & \\
$\quad$ Low proficiency & 9.14 & 3.77 & $-4.200^{* * *}$ \\
High proficiency & & & \\
Listening times & 34.00 & 13.42 & $-2.416^{*}$ \\
Low proficiency & 56.38 & 15.39 & \\
High proficiency & & & \\
Listened to times & 4.75 & 3.13 & .556 \\
$\quad$ Low proficiency & 11.67 & 9.57 & \\
High proficiency & 101.50 & 34.12 & $-6.174^{* * *}$ \\
Rehearsal times & 95.52 & 19.79 & \\
$\quad \begin{array}{l}\text { Low proficiency } \\
\text { High proficiency }\end{array}$ & & & \\
Listening involvement & 2.45 & 3.22 & \\
$\quad$ Low proficiency & 7.20 & &
\end{tabular}

Results of statistical analysis showed that a significant difference existed in the system usage between the low and high proficiency groups regarding listening diversity $(\mathrm{t}=3.882, \mathrm{p}<0.01)$, listening times $(\mathrm{t}=-4.200$, $\mathrm{p}<0.001)$, listened to times $(\mathrm{t}=-2.416, \mathrm{p}<0.05)$, and listening involvement $(\mathrm{t}=-6.174, \mathrm{p}<0.001)$. This result suggests that students in the high-proficiency group used the system much more frequently for listening and they were much more involved in listening practice than those in the low-proficiency group. On the other hand, students in the low-proficiency group applied the system more often for listening to diverse students than students in the high-proficiency group. This shows that students in the high-proficiency group did better than those in the low-proficiency group in choosing their listening partners and spending more time listening to their peers' voices. As a result, more guidance should be given in the future to students in the low-proficiency group, so that they are able to choose their partners more carefully and pay more attention to the recorded voices. 
The field notes and interviews revealed that students felt very interested in practicing English speaking at their own pace, such as in Activity 3, role-play, since they liked talking face-to-face in their own way and in a relaxing atmosphere. In addition, the function of being listened to on mobile devices made students feel more serious and put more effort into English speaking practice, such as in Activity 4, "You speak, then I Speak".

\section{Conclusions}

This study analysed related research on technology-assisted EFL learning and some limitations (e.g. related to learning activities) were revealed. Therefore, this study designed better and more specific learning activities supported by mobile learning technology to facilitate EFL speaking and listening skills. This study investigated how students perceive such learning activities and the relationship between their perceptions, intentions, and actual system usage for practicing EFL speaking and listening skills. Furthermore, this study examined what type of practice can have positive learning outcomes by providing objective evidence. Based on obtained findings, this study provided several implications and suggestions for future study design and research.

A few limitations need to be acknowledged regarding this study. The experienced English teacher designed the pre- and post-test in this study and ensured the tests items had a similar structure, different content, and similar degree of difficulty; however, the tests items still need to be designed by using a scientific approach, i.e. a conscientious analysis needs to be done to prove that the difficulty of the tests are similar. It was mentioned earlier that having insufficient opportunities to practice EFL skills is a problem for EFL students in countries within the Asia-Pacific region. However, this study attempted to support Taiwanese elementary school students to develop their listening and speaking skills by using a mobile learning system. Another limitation is the absence of a control group so that this study could not evidently compare learning performance of students who used the mobile learning system with that of students who used traditional tools (i.e. pen and paper). The relatively small sample size is also one limitation of this study. For this reason, these findings cannot be generalized to the broader community merely based on this study. In the future, the focus of this study will be extended. For example students will still use mobile devices but utilize their mobility to explore and interact with surrounding authentic environments outside of school walls. That is, students will be able to practice listening and speaking skills with learning content related to their daily life, e.g. playground or home. Further, the future study will include a control group, increase sample size, and apply this learning system to student cohorts in countries outside of the Asia-Pacific region.

\section{Acknowledgements}

This research is partially supported by the International Research-Intensive Center of Excellence Program of NTNU and the Ministry of Science and Technology of the Republic of China, Taiwan, under the grant numbers NSC 103-2911-I-003-301, NSC 102-3113-P-006-019-, NSC 101-2511-S-008-012MY3, NSC 101-2511-S-008-013-MY3, and NSC 100-2511-S-006-015-MY3.

\section{References}

Bueschel, A. C. (2008). Listening to students about learning. Stanford, CA: Carnegie Foundation for the Advancement of Teaching.

Chen, N. S., Hsieh, S. W., \& Kinshuk. (2008). Effects of short-term memory and content representation type on mobile language Learning. Language Learning \& Technology, 12(3), 93-113.

Cheon, H. (2003). The viability of computer mediated communication in the Korean secondary EFL classroom. Asian EFL Journal, 5(1), 1-61.

Creswell, J. W. (2012). Educational research: planning, conducting, and evaluating quantitative and qualitative research. Upper Saddle Creek, NJ: Pearson Education.

Davis, F. D. (1989). Perceived usefulness, perceived ease of use, and user acceptance of information technology. MIS Quarterly, 13(3), 189-211.

Ghoneim, N. M. M. (2013). The listening comprehension strategies used by college students to cope with the aural problems in EFL classes: An analytical study. English Language Teaching, 6(2), 100-112. 
Hazan, V., Sennema, A., Iba, M., \& Faulkner, A. (2005). Effect of audiovisual perceptual training on the perception and production of consonants by Japanese learners of English. Speech Communication, 47, 360-378.

Huang, Y. M., \& Chiu, P. S. (2014). The effectiveness of a meaningful learning-based evaluation model for context-aware mobile learning. British Journal of Educational Technology. doi: 10.1111/bjet.12147

Huang, Y. M., Chiu, P. S., Liu, T. C., \& Chen, T. S. (2011). The design and implementation of a meaningful learning-based evaluation method for ubiquitous learning. Computers \& Education, 57(4), 2291-2302.

Huang, Y. M., Huang, Y. M., Huang, S. H., \& Lin, Y. T. (2012). A ubiquitous English vocabulary learning system: Evidence of active/passive attitudes vs. usefulness/ease-of-use. Computers \& Education, 58(1), 273-282.

Huang, Y. M., Huang, Y. M., Liu, C. H., \& Tsai, C. C. (2013). Applying social tagging to manage cognitive load in a Web 2.0 self-learning environment. Interactive Learning Environments, 21(3), 273-289.

Huang, Y. M., Huang, S. H., \& Wu, T. T. (2014). Embedding diagnostic mechanisms in a digital game for learning mathematics. Educational Technology Research and Development, 62(2), 187-207.

Huang, Y. M., \& Wu, T. T. (2011). A systematic approach for learner group composition utilizing ulearning portfolio. Educational Technology \& Society, 14(3), 102-117.

Hwang, W. Y., \& Chen, H. S. L. (2013). Users' familiar situational contexts facilitate the practice of EFL in elementary schools with mobile devices. Computer Assisted Language Learning, 26(2), 101-125.

Hwang, W. Y., Chen, H. S. L., Shadiev, R., Huang, Y. M., \& Chen, C. Y. (2012). Improving English as a foreign language writing in elementary schools using mobile devices in familiar situational contexts. Computer Assisted Language Learning, 27(5), 359-378. DOI:10.1080/09588221.2012.733711

Hwang, W. Y. \& Shadiev, R. (2014). Cognitive diffusion model with user-oriented context-to-text recognition for learning to promote high level cognitive processes. Knowledge Management \& ELearning, 6(1), 30-48.

Hwang, W. Y., Shadiev, R., Hsu, J. L., Huang, Y. M., Hsu, G. L., \& Lin, Y. C. (in press). Effects of storytelling to facilitate EFL speaking using web-based multimedia system. Computer Assisted Language Learning, (ahead-of-print), 1-27. DOI: 10.1080/09588221.2014.927367

Hwang, W. Y., Shadiev, R., \& Huang, S. M. (2011). A study of a multimedia web annotation system and its effect on the EFL writing and speaking performance of junior high school students. ReCALL, 23(2), 160-180.

Hwang, W. Y., Wu, S. Y., \& Su, J. H. (2008). A study of listening diversity and speaking for English learning with mobile device supports. Lecture Notes in Computer Science, 5353, 748-757.

Jeng, Y. L., Wu, T. T., Huang, Y. M., Tan, Q., \& Yang, S. J. H. (2010). The add-on impact of mobile applications in learning strategies: a review study. Educational Technology \& Society, 13(3), 3-11.

Kukulska-Hulme, A., \& Shield, L. (2008). An overview of mobile assisted language learning: From content delivery to supported collaboration and interaction. ReCALL, 20(3), 249-252.

Liang, T. H., \& Huang, Y. M. (2014). An investigation of reading rate patterns and retrieval outcomes of elementary school students with e-books. Educational Technology \& Society, 17(1), 218-230.

Liu, T. Y., \& Chu, Y. L. (2010). Using ubiquitous games in an English listening and speaking course: Impact on learning outcomes and motivation. Computers \& Education, 55(2), 630-643.

Moon, J. W., \& Kim, Y. G. (2001). Extending the TAM for a world-wide-web context. Information \& Management, 38(4), 217-230.

Murray, L., \& Barnes, A. (1998). Beyond the "wow" factor - Evaluating multimedia language learning software from a pedagogical viewpoint. System, 26(2), 249-259.

Nah, K. C., White, P., \& Sussex, R. (2008). The potential of using a mobile phone to access the Internet for learning EFL listening skills within a Korean context. ReCALL, 20(03), 331-347.

Shadiev, R., Hwang, W. Y., Huang, Y. M., \& Liu, C. J. (in press). Investigating applications of speech to text recognition for face to face seminar to assist learning of non-native English participants. Technology, Pedagogy and Education.

Shadiev, R., Hwang, W. Y., Chen, N. S., \& Huang, Y. M. (in press). Review of Speech-to-Text Recognition technology for enhancing online and face-to-face learning. Journal of Educational Technology and Society.

Sun, K. T., Huang, Y. M., \& Liu, M. C. (2011). A WordNet-based near-synonyms and similar-looking word learning system. Educational Technology \& Society, 14(1), 121-134. 
Thorton, P., \& Houser, C. (2005). Using mobile phones in English education in Japan. Journal of Computer Assisted Learning, 21, 217-228.

Tsou, W. (2005). Improving speaking skills through instruction in oral classroom participation. Foreign Language Annals, 38, 46-55.

Venkatesh, V., \& Davis, F. D. (2000). A theoretical extension of the technology acceptance model: Four longitudinal field studies. Management Science, 46(2), 186-204.

Wang, M., Shen, R., Novak, D., \& Pan, X. (2009). The impact of mobile learning on students' learning behaviours and performance: Report from a large blended classroom. British Journal of Educational Technology, 40(4), 673-695.

Wu, T. T., Sung, T. W., Huang, Y. M., Yang, C. S., \& Yang, J. T. (2011). Ubiquitous English learning system with dynamic personalized guidance of learning portfolio. Educational Technology \& Society, 14(4), 164-180.

Corresponding author: Yueh-Min Huang, huang@mail.ncku.edu.tw

Australasian Journal of Educational Technology (C) 2014.

Please cite as: Hwang, W-Y.Huang, Y-M., Shadiev, R., Wu, S-Y., \& Chen, S-L. (2014). Effects of using mobile devices on English listening diversity and speaking for EFL elementary students. Australasian Journal of Educational Technology, 30(5), 503-516. 